\title{
Entre el diletantismo y la autoafirmación: de la aficionada a la mujer moderna
}

\author{
Irene Marina Pérez Méndez ${ }^{1}$
}

Recibido: 26 de enero de 2018 / Aceptado: 2 de mayo de 2018

Resumen. El presente artículo ahonda en las relaciones mujer-arte entre los siglos XIX y XX en España, etapas de transición hacia una participación femenina como sujeto creador inédita por su temática y significación. Se trata de mostrar la evolución que se registra en el panorama artístico femenino desde la condescendencia decimonónica que permitía un acercamiento de las mujeres a la pintura como elemento de distracción, hasta su conquista, ya en las primeras décadas del siglo XX, por parte de un nuevo prototipo de mujer que desafió la estructura patriarcal a través de transgresiones estéticas y sociales sin precedentes. Para ilustrar esta realidad se ha escogido el ejemplo paradigmático de la artista zamorana Delhy Tejero, reflejo de la vanguardia española en apariencia, implicación y trayectoria profesional.

Palabras clave: Mujer Moderna; Delhy Tejero; garçonne; bruja; aficionada.

\section{[en] In between dilettantism and self-assertion: amateur to New Woman}

\begin{abstract}
The aim of this paper is to deepen into women-art relationships between the 19th and 20th centuries in Spain as stages of transition to a female participation as art maker unimaginable by its theme and significance. It is about showing the evolution of the feminine artistic panorama from the nineteenth century condescension, that allowed women to approach painting as an element of distraction, to its conquest, during the first decades of the 20th century, by a new prototype of women who challenged the patriarchal structure through both an unprecedented aesthetic and social transgressions. To illustrate this achievement, we have chosen the paradigmatic example of the artist Delhy Tejero, a unique reflection of the Spanish avant-garde in appearance, involvement and professional career.
\end{abstract}

Keywords: New Woman; Delhy Tejero; garçonne; witch; amateur.

Sumario. 1. La mujer artista: mito y realidad. 1.1. Artista y modelo. 1.2. La pintura como adorno. 2. Hacia la emancipación: Delhy Tejero como paradigma de la Mujer Moderna. 2.1. Acerca de la Mujer Moderna. 2.2. Delhy Tejero: la bruja moderna.

Cómo citar: Pérez Méndez, I. M. (2018) Entre el diletantismo y la autoafirmación: de la aficionada a la mujer moderna, en Anales de Historia del Arte nº 28 (2018), 263-279.

1 Universidad de Oviedo

perez.irenemarina@gmail.com

Código ORCID 0000-0002-4352-255X 


\section{La mujer artista: mito y realidad}

El paso de la mujer de objeto a sujeto creador se hace efectivo en el siglo XX, cuando la pintora alcanza un estatus de relativa igualdad con respecto al sujeto varón. La ausencia de grandes artistas femeninas a lo largo de los siglos anteriores no se debe, empero, a una falta de capacidad innata y talento para el arte en el sexo femenino. Lo connatural reside, más bien, en la masculinidad latente ya en el propio lenguaje dentro del concepto nuclear de la Historia del arte: la noción de «genio». Históricamente genialidad y maestría, como categorías dentro del discurso artístico occidental, se han venido asociando a la masculinidad, culminando en el Romanticismo la figura excelsa del varón genial $^{2}$. La omisión de la mujer en el perímetro de la genialidad radica, precisamente, en su condición no masculina. Una exclusión que se hace efectiva cuando se consolida definitivamente la separación de las esferas de lo público y lo doméstico. La figura de una genia en el siglo XIX se revelaba entonces imposible, «ninguna de las dos imágenes prevalentes del artista (el gentleman profesional y el outisder bohemio) parecían compatibles con las definiciones victorianas de la mujer «respetable», esto es, domesticada, decorativa y maternal» ${ }^{3}$. Las nuevas teorías científicas, inauguradas con El origen de las especies (1859) articularon de manera legítima esa separación física, espacial, entre hombres y mujeres, concluyendo en la natural incapacidad intelectual de las últimas, que debían reservar toda su energía vital para la procreación ${ }^{4}$.Creación intelectual versus creación física.

Lo cierto es que la práctica artística nunca fue un campo desconocido para la mujer. En 1981 Griselda Pollock y Rozsika Parker contaban en uno de los textos más significativos para la historia del arte feminista, Old Mistresses. Women, art and ideology cómo aun en los convenientes silencios historiográficos es posible hallar pruebas de un arte producido por mujeres ${ }^{5}$ reconocido incluso dentro de la producción monográfica de Giorgio Vasari, referente histórico para el cálculo de la genialidad. Las alusiones de este último a grandes artistas renacentistas como Sofonisba Anguissola ponen de relieve el estrato socioeconómico necesario que garantizaba a estas mujeres un porvenir en el $\operatorname{arte}^{6}$ y refuerza la teoría que Linda Nochlin tan bien esgrimió en Why have there been no great women artists? En efecto, la mujer siempre ha estado presente en la esfera artística, pero lamentablemente no podemos afirmar que existan equivalentes femeninos a los grandes artistas como Rembrandt, Miguel Ángel o Picasso, «del mismo modo que tampoco hay equivalentes afroamericanos para De Kooning o Warhol» ${ }^{7}$ : no existía un marco institucional y social que permitiese tal amplitud.

\footnotetext{
Mayayo, P. (2003). Historias de mujeres, historias del arte. Madrid: Cátedra, 67.

Ibíd., 169.

Dijkstra, B. (1994). Ídolos de perversidad. Madrid: Debate, 161.

Pollock, G. y Park, R. (2013). Old Mistresses. Women, art and ideology. London: I.B. Tauris, 3.

«During the period we call the Renaissance, women's practice in the fine arts was affected by new factors. Increasingly they ceased to have access to conventional forms of training. Some were excluded from the newly organized artist's workshops. We find instead that women became artists by taking advantage of their different circumstances. While male artistis tended to come from an artisan or petit-bourgeois background, and rarely from the aristocracy, the significant women artists in the Reinassance were bron into nobility». Ibíd., 17.

7 Nochlin, Linda. (30 mayo de 2015) Why have there been no great women artists?, Artnews, Obtenido de http:// www.artnews.com/2015/05/30/why-have-there-been-no-great-women-artists/ [Consulta: 3 de octubre de 2017]
} 
Lejos de ser una disciplina completamente libre, autónoma, merced al sujeto creador, la actividad artística se estructura a través de unos resortes sociales que conscientemente se han encargado de coartar la inclusión femenina, de acuerdo a un sistema excluyente de enseñanza, mecenazgo, crítica y creencia en la genialidad ${ }^{8}$

Pero si las artistas han desarrollado su actividad a pesar de ello, quizás su proeza profesional deba estimarse en función a las relaciones establecidas con esas estructuras oficiales que descartaban su participación en la esfera artística. Como arguye Griselda Pollock, la cuestión debe escapar a los argumentos tajantes de Nochlin que, por lógica, dejarían fuera la posibilidad de cualquier mujer dedicada al $\operatorname{arte}^{9} \mathrm{y}$ centrarse en el modo en que muchas sortearon los obstáculos específicos, sexuales y de clase, en sus intervenciones artísticas. Si la participación femenina en la producción cultural ya no se discute, parece claro que la problemática pasa irremediablemente por el enfoque otorgado desde Historia del arte: una disciplina que colabora activamente en el discurso ideológico patriarcal de la diferencia sexual, y que por tanto debe «ser entendida en sí misma como una serie de prácticas de representación que producen de manera activa definiciones de la diferencia sexual y contribuyen a la configuración actual de las políticas sexuales y de las relaciones de poder» ${ }^{10}$.

\subsection{Artista y modelo}

Frente a su rechazo como sujeto activo, la entrada de la mujer dentro del microcosmos artístico se cataliza, de manera práctica, por medio de su papel como modelo. Culmen y núcleo de la cosificación que históricamente los artistas habían practicado con respecto a la figura femenina, el binomio «el pintor y la modelo» terminó por imprimir un carácter totalmente femenino a un objeto-modelo que, efectivamente, también era masculino. A este respecto, fue precisamente el peligro de la entereza del modelo masculino ante la presencia femenina uno de los argumentos recurrentes de los opositores a la entrada de mujeres en las instituciones artísticas $^{11}$.

La modelo, femenino singular, se asume como parte subsidiaria de su opuesto masculino singular, el pintor. Bien podríamos incluso hablar de modelos, en plural, frente a un creador completamente único y singular, genial. Una apreciación sensiblemente distinta que más que referirse a la estratificación social de dichas modelos -de hecho diversa y por supuesto no privativa de los estatus más acomodados de la sociedad-, pretende incidir, de nuevo, en la cuestión de la tipificación de la mujer.

Las musas y los modelos recibían un tratamiento distinto, en tanto que su misión resultaba tangencialmente opuesta. Frente a las virtudes más enérgicas loadas en los varones que hacían hincapié en su asimilación con los héroes clásicos, la pasividad se coronó como aptitud indispensable para la modelo femenina ${ }^{12}$. Del mismo modo,

\footnotetext{
Ibíd.

Pollock, G. y Parker, R. (2013). Op. cit., 49.

Pollock, G. (2013). Visión y diferencia. Feminismo, feminidad e historias del arte. Buenos Aires: Fiordo, 38.

11 Me refiero aquí a la cuestión del desnudo que tan bien resume Patricia Mayayo cuando analiza la exclusión de las artistas femeninas de L'Ecole des Beaux-Arts. Un temor al quebramiento de los valores tradicionales soterrado bajo la alarma de una posible masculinización de la mujer.

12 «La ausencia de temperamento era uno de los requisitos más valorados, era mejor una mujer de carácter apaciguado y tranquilo que una mujer con carácter impulsivo y nervioso». Val Cubero, A. (2001). La percepción
} 
la brecha de edad entre hombres y mujeres distinguía entre la edad avanzada de los primeros y la preferencia por la juventud en las modelos. Valga señalar que el anhelo romántico de libertad encuentra en la infancia el cauce más expresivo de la naturalidad humana, sin las cortapisas impuestas a los instintos sexuales más primarios. Tal era, al menos, la doctrina educativa rousseauniana, cimentada sobre la natural bondad del hombre. No corresponde a este trabajo el reflexionar acerca de la posibilidad de una pulsión erótica en las representaciones infantiles y juveniles, sin embargo se hace necesario recordar que los límites de edad de las modelos pintadas siempre se han resuelto muy difusos.

Algunos estudios afirman que la tónica general en el tratamiento de la infancia resulta ciertamente reverencial ${ }^{13}$. Al contrario, Dijkstra observa una tendencia más alarmante que rebasa los límites de la inocua adulación: las imágenes infantiles y adolescentes actuaban como una vía más de representación de la inferioridad de la mujer y su dependencia del varón. Su inmaculada y tierna pureza terminó por convertirse no sólo en imagen de la femineidad, mas en la expresión del turbado anhelo masculino por una dominación que se resolvía de este modo posible. La aparente veneración terminó por alumbrar una suerte de pornografía infantil que vertía en el cuerpo aniñado los ideales esperados para la mujer adulta ${ }^{14}$.

Como contrapartida al candor infantil, manifiesta era la desacreditación del estatus social de la modelo, tan frecuentemente comparado y asimilado al de la prostituta. Máxima cimentada en una supuesta promiscuidad que parecía asociarse a la facilidad y predisposición de ambas profesiones hacia el desnudo.

Una reflexión compartida por la mayoría pero expresada, en algunos casos, de modo más condescendiente y socarrón. Tal es el ejemplo que hallamos en el capítulo destinado precisamente a tal profesión: La modelo, recogido en el segundo volumen de la obra Las españolas pintadas por los españoles (1871), un auténtico catálogo idiosincrásico heredero de las phisiologies francesas, que considera pormenorizadamente los diferentes tipos femeninos de la España del XIX. Con respecto a las modelos, el autor reitera lo desvergonzado de un trabajo que se realiza por la imperiosa necesidad de la mujer de mostrarse tal como Dios la hizo; más un fin que un medio, la desnudez se muestra como una gratificación personal: «Vive entre pintores porque se halla en su centro; sacadla de esa vida, prometedla ganar más con menos trabajo y más decorosamente, y no lo aceptará» ${ }^{15}$.

del desnudo femenino en el art. Siglos XVIII-XIX. Pintura, mujer y sociedad (Tesis doctoral). Universidad Complutense de Madrid, Madrid, 286.

13 «Los artistas no parecen traspasar los límites permitidos o comúnmente aceptados de la edad de las modelos en los cuadros [...] el arte parece tener límites morales. Los artistas aceptan a la niña como modelo cuando se trata de realizar retratos infantiles, cuando la alegoría representada determina su inclusión en el cuadro o cuando la idea filosófica se ve necesitada de la figura de una niña para ser explicada. No de otra forma aparecerá la infancia femenina al desnudo» (García Torralbo, M. C., y Sánchez Concha, F. J. (2011). Niña-mujer objeto de arte: la sexualidad femenina en la pintura, III Congreso virtual sobre Historia de las Mujeres, Asociación de Amigos del Archivo Histórico Provincial de Jaén, 6. Obtenido de: http://idus.us.es/xmlui/handle/11441/52093 [Consulta: 2 de octubre de 2017]

14 «Incapaz de relacionarse con mujeres que fueran fuertes e independientes y que osaran plantear exigencias, el hombre de finales del XIX moldeó a la niña según la imagen de una mujer a la que podía dominar. El desamparo, la debilidad y la docilidad pasiva e ignorante que ya no podía encontrar en la adulta empezó a atribuirla a la niña». Dijkstra, B. (1994). Op. cit., 194.

15 Robert, R. (1871). Las españolas pintadas por los españoles: colección de estudios acerca de los aspectos, estados, costumbres y cualidades generales de nuestras contemporáneas, Tomo II, Alicante: Biblioteca Virtual Miguel de Cervantes (2008), 109. http://www.cervantesvirtual.com/nd/ark:/59851/bmcsn0p6 
Y más aún cuando de su falta de escrúpulos al desnudarse se conjetura una entrega corporal total:

Es la antigua Pitonisa, cuyos misterios estaban velados a los profanos. Pues bien, a esa misma mujer hacedla creer que sois pintor; menos aún: decidla que sois un gran aficionado y comprador de cuadros, y caerá el velo que os impedía contemplarla, o lo que es lo mismo, os permitirá entrar en su misterioso templo. ${ }^{16}$

Nos encontramos, de nuevo, ante los parámetros de la decencia que articulaban la realidad social de la mujer y que, precisamente, la alejaban de desempeñar una labor artística equiparable a la del varón. Resulta paradójico que la única entrada de la mujer al universo privado del artista, cuando no se ve comparada con el oficio desempeñado en un burde $1^{17}$ es motivo de oprobio y estigma social ${ }^{18}$. En ambos casos, su situación es cuestionada por idénticos prejuicios morales ante los que únicamente cabe recordar el lema que las Guerrilla Girls blandieron ya en 1989: Do women have to be naked to get into the Met. Museum?

\subsection{La pintura como adorno}

Hemos comentado ya la imposibilidad del sexo femenino para engrosar el discurso histórico-artístico en las mismas condiciones que los varones. También se ha comentado que la pintura, lejos de ser un campo vetado para la mujer, era practicada en más de una ocasión de manera ciertamente libre. Se hace necesario explicar, sin embargo, qué clase de pintura estaba reservada al sexo femenino en la sociedad decimonónica, y más aún bajo qué circunstancias.

Una vez más, se presenta la distinción entre los campos masculino y femenino, que en este caso se vehicula a través del concepto que del arte cada grupo debe ejercitar. En este sentido, la libertad de la mujer para practicar la pintura no debe confundirse con la autonomía de esa actividad. Precisamente la pintura actuaba como un atributo más dentro de la concepción objetual y doméstica de la mujer. Hablamos entonces de adorno, entretenimiento y distracción, y no de actividad profesional remunerada y vocacional.

El ejercicio de la pintura -más bien del dibujo- se observa como modo más adecuado, junto con el cultivo de la música, el bordado o la danza, de perfilar una sensibilidad que se presupone naturalmente femenina. Es posible afirmar sin miramientos que todas estas enseñanzas pivotaban en torno al concepto de habilidad social, lo cual resulta perfectamente comprensible si la misión de toda mujer pasaba por lograr un compromiso matrimonial. Si el destino de la mujer es de mero adorno del ámbito

16 Ibíd., 109.

17 «Las similitudes entre el trabajo de «modelo» y el de prostituta se vieron además favorecidas porque ambas ocupaciones tenían lugar en «espacios privados», lo que hacía que el taller del «artista« fuera visto como la sala de un burdel donde las mujeres desnudas posaban y accedían a los deseos de quienes las retrataban». Val Cubero, A. (2001). Op. cit., 282.

18 «La modelo, para concluir, es una mujer como otra cualquiera. Si veis en la calle a una joven que se mete en un portal para atarse una liga, no os fieis de ese pudor de doublé, quizá es una modelo». Robert, R. (1871). Op. cit., 113. 
privado del hombre, no es de extrañar que sus actividades y atributos se contemplen bajo la misma órbita subsidiaria.

Y si la educación artística pretende ser mero ornato, del mismo modo serán los temas a representar. En Cartas sobre la educación del bello sexo, el capítulo destinado precisamente a la educación de las artes, no deja lugar a dudas a este respecto:

Las flores, el paisaje y el género comúnmente llamado «de adorno», me parecen más propios de una mujer, que la figura humana, estudio mucho más complicado que los otros y que conduce a la pintura al óleo, que exige demasiado tiempo y preparativos. Dejemos estas regiones elevadas del cultivo de las artes a los que se sienten animados por el fuego de la inspiración, o los que viven de sus productos. Considerémoslas como ornatos de cualidades más sólidas, no como tareas exclusivas y profesionales. ${ }^{19}$

Parece lógico que las naturalezas muertas y las flores triunfen entre las pinturas resueltas por mujeres. La dificultad para el estudio y representación de la figura humana, habida cuenta las trabas académicas impuestas a las mujeres, conlleva un predominio de aquello que es más próximo a su realidad cotidiana. Es necesario considerar no obstante la predilección del gusto burgués por los temas florales y delicados, herederos del academicismo dieciochesco ${ }^{20}$.

También el paisaje es un tema propicio para el ejercicio pictórico femenino. Destaca, en este sentido, el ejemplo del paisaje dual español analizado por $\mathrm{M}^{\mathrm{a}}$ del Carmen Peña ${ }^{21}$ que presenta una oposición de conceptos masculinos y femeninos. A partir de los adjetivos reservados a cada concepto se concluye en el encanto y armonía femeninas, que redundan en una vulgaridad derivada de su pasiva gestación; lo masculino queda vinculado a los contrastes abruptos y los juegos de fuerzas opuestas, en una línea mucho más compleja y virtuosa ${ }^{22}$. Como vemos, se trata de otra modalidad de expresión de los ya conocidos estereotipos conductuales, que vienen a imbricarse en una teoría y práctica del paisaje desarrollada en España con carácter retardatario.

En cuanto a la afirmación que Joaquín de Mora realizaba con respecto a lo propio de una mujer ${ }^{23}$ en la pintura, poco más se puede añadir a lo que sería axioma en todos los manuales destinados a la buena educación de las señoritas. En la misma línea, otros

19 Mora, J. J. de. (1829). Carta V. Educación artística. Dibujo, bordado, música y baile. Moderación en la adquisición y el cultivo de las artes. En Cartas sobre la educación del bello sexo. Habana: Imprenta del Gobierno y Capitanía General por S.M. Biblioteca Digital AECID, 62. http://bibliotecadigital.aecid.es/bibliodig/es/consulta/registro.cmd?id=392

20 Diego, E. de. (2009). La mujer y la pintura del XIX español. Cuatrocientas olvidadas y algunas más. Madrid: Cátedra, 391

21 Peña, M. C. (1984). El concepto de lo femenino y lo masculino en la teoría del paisaje español. En VV.AA., La imagen de la mujer en el arte español. III Jornadas de Investigación Interdisciplinaria sobre la mujer (pp. 141148). Madrid: Ediciones de la Universidad Autónoma de Madrid.

22 Ibíd., 145-146.

23 Baste recordar las sugerencias de Michelet sobre lo adecuado para la mujer en el campo de las artes «Por lo que respecta al dibujo, le proporcionará los más nobles modelos de la antigua escuela florentina, como son vírgenes de Rafael y discretos cuadros de Poussin, pues sería una impiedad enseñarla el Corregio con sus estremecimientos; sería inmoral que le explicase la grandeza enfermiza, la gracia febril, siniestra, de la moribunda Italia en la sonrisa de la Joconda [...] peor para la joven que comprenda ese movimiento y perciba ese no sé qué que se escapa de su boca amorosa. En consecuencia, sabría demasiado». Michelet, J. (1930). La mujer. Barcelona: Luis Tasso, 166. 
intelectuales como José Parada y Santín sostienen la práctica de los estudios artísticos como entretenimiento siempre potenciador de valores morales que supongan la mejor educación de los hijos, del hogar y la familia ${ }^{24}$ De ello podemos extraer además la importancia de la inevitable división de esferas entre ese cultivo exclusivo y profesional de las artes, y su papel ornamental de complemento más necesario que circunstancial ${ }^{25}$.

Para Estrella de Diego, la división entre diletante y profesional que se articula en el XIX marcará la tónica para la valoración de la mujer en el espectro artístico. Se distinguen en estos momentos la figura del artista que lo es por afición, del que hace del arte un medio de vida. La única práctica disponible para la mujer de acuerdo a la relación que mantenía con la pintura pasaba irremediablemente por el diletantismo. Una práctica, en cualquier caso, difícil de desarrollar de manera equivalente a la del pintor de afición, independiente en términos económicos y libre de cargas domésticas ${ }^{26}$.

Sin una estructura que las amparase, muy lejos del estatus de genio y por ello ajenas a cualquier éxito profesional, la mujer artista se convertía no tanto en una rara avis como en una aficionada.

Curioso es entonces cuando leemos acerca de La aficionad ${ }^{27}$ y observamos la denuncia hacia la hipertrofia de esa educación artística femenina. La mujer que ni es ni pretende ser una artista, la que es solamente aficionada, resultó ser una pesadilla para esos pobres maridos que no concebían de otro modo la afición artística de sus mujeres sino como un acercamiento silencioso, pausado, modesto y discreto. Una cortés reverencia hacia un campo, el artístico, soberano e incomprensible para ellas. Eran éstas, «las que no se exhiben, ni anhelan brillar, ni buscan aplausos» el modelo ejemplar:

Estas, lejos de ser un martirio, constituyen la alegría de su familia y hacen el encanto de su hogar. Modestas sin afectación, porque conocen la dificultad del arte a que rinden culto y al que consagran ratos de descanso y esparcimiento, ni ocultan su habilidad, ni la pasean de casa de en casa. La afición es entonces un adorno más en la mujer y tiene muchas probabilidades de llegar a ser una virtud como fuente inagotable de buenos sentimientos y de dulzura de carácter. ${ }^{28}$

Por contrapartida, aquellas mujeres, esposas, hijas o prometidas, que osaran desenvolverse con demasiada soltura y protagonismo en una reunión social, aquéllas que mendigaban aplausos, suponían el mayor de los estorbos. Toda una declaración de intenciones con respecto a lo que de esos adornos se esperaba: el recreo inocente y agradable proporcionado por tales actividades no podía devenir en una actitud demasiado pretenciosa e insistente.

Solamente una afición.

24 Parada y Santín citado en Muñoz López, P. (2003). Mujeres españolas en las artes plásticas. Madrid: Síntesis, 106.

25 «Una mujer amable, templada, modesta, que inspecciona y dirige todas las operaciones de su familia, que educa a sus hijos y hace feliz al compañero de su suerte; si además de estas prendas esenciales, sabe tomar parte en una conversación interesante, dibujar con gusto y corrección, cantar con alma y método y descifrar en el piano una sonata, reúne todo cuanto puede atraerle el respeto y el cariño». Mora, J. J. de. (1829). Op. cit., 70-71.

26 Estrella de Diego lo explica así: «esa soledad e independencia económica [del hombre] eran impensables para las mujeres. De solteras, sometidas al padre, de casadas, al marido, y de huérfanas; a un tutor que controlaba su dinero; las más de las veces, no llegaban a disponer jamás del patrimonio necesario para llevar a cabo un trabajo serio en el arte, salvo en el caso de enviudar». Diego, E. de. (2009). Op. cit., 300.

27 Robert, R. (1871). Op. cit., 29-39.

28 Ibíd., 39 


\section{Hacia la emancipación: Delhy Tejero como paradigma de la Mujer Moderna}

\subsection{Acerca de la Mujer Moderna}

Hasta este momento se ha insistido en la división entre el universo público y el privado y es cierto que la presencia de la mujer en el mercado artístico de finales del XIX altera, de manera más o menos contundente, su situación como mera aficionada o diletante. Incluso aunque las lagunas de las obras realizadas por mujeres en el ámbito público quedan socavadas por los testimonios ofrecidos por Estrella de Diego y Pilar Muñoz López, no debemos confundir esta feminización con un asalto a la esfera pública, sino más bien con una apertura premeditada por parte del sexo dominante. Cuando el terreno de las artes aplicadas experimentó una creciente demanda en los años finales del siglo XIX, al tiempo que la pintura de historia se desdeña por su imposible aplicación en la decoración del hogar burgués, la labor femenina se vio necesaria y eficaz; ¿hablamos de arte o de artesanía? Quizá no fue fortuito ese desinterés paulatino del hombre en actividades que progresivamente se afianzaron en el dominio femenino. Tal vez sea irrelevante que esto ocurra mientras el estadio supremo -el de la pintura- continúe inalcanzable para la mujer.

La auténtica conquista del territorio artístico germina, como se ha dicho, en el siglo XX. La metáfora expresada por Ana María Arias de Cossío ${ }^{29}$ en referencia a las representaciones femeninas en España en los albores del nuevo siglo, es realmente ilustrativa del nefasto pronóstico de progreso de la mujer ${ }^{30}$. La posición social de la mujer en la España de entresiglos continuaba la estela tradicional de la moralidad defendida por la Iglesia, y la falta de una preparación intelectual que la Gloriosa no logró enmendar. Legalmente, la mujer, como menor de edad e incapaz de ejercer autonomía jurídica, se hallaba al amparo de su progenitor o su marido.

Cuando se hizo posible para la mujer traspasar el umbral del hogar y acceder a la esfera artística como creadora, otrora vetada; cuando ventana y balcón no salvaron un abismo insondable, la organicidad temática de su pintura se orientó hacia el espejo del alma. Frente a la bicéfala Galatea decimonónica, madre o bestia, emergen infinitas imágenes, tantas como artistas, nacidas de una necesidad vital, humana, de expresión y articulación identitaria tantas veces lacerada por la mirada inquisitiva del hombre y genio creador.

Desde el momento en el que la mujer afronta su propia imagen y se sabe independiente de la mirada masculina, comenzará el camino de su definición como mujer y, por lo tanto, su reinvención de la feminidad que ahora desborda las caducas estructuras patriarcales de representación ${ }^{31}$. De tal suerte, la captación de la apariencia física va más allá de una elección temática o la voluntad de la autorrepresentación, y se convierte de por sí en un acto vindicativo por el derecho al reconocimiento del intelecto y la creatividad de la escritora, la artista o la filósofa españolas ${ }^{32}$.

29 Arias de Cossío, A. M. (2002). Mujeres que miran al cambio de siglo. En Quiles Faz, A. y Sauret Guerrero, M. T. (Coord.), Prototipos e imágenes de la mujer en los siglos XIX y XX (pp. 99-108). Málaga: Servicio de Publicaciones de la Universidad de Málaga.

30 La autora reflexiona acerca de los límites de lo masculino y lo femenino, proponiendo la ventana y el balcón como frontera entre ese mundo privado y doméstico, y el exterior, público.

31 Serrano de Haro, A. (2007). Imágenes de lo femenino en el arte: atisbos y atavismos. Polis: Revista Latinoamericana, (17), 1-2.

32 Barrera López, B. (2014). Personificación e iconografía de la mujer moderna. Sus protagonistas de principios del siglo XX en España. Trocadero: Revista de Historia Moderna y Contemporánea, (26), 226. Obtenido de: http://revistas.uca.es/index.php/trocadero/article/view/2099/1917 [Consulta: 4 de octubre de 2017] 
Como comenta Inmaculada Plaza Aguado a propósito de las escritoras españolas de preguerra ${ }^{33}$ la actividad artística de cualquier índole rebasa por sus inherentes aspiraciones comunicativas la creación más solipsista del autorretrato, y denota una clara voluntad de lograr un reconocimiento público, un hueco en el establishment que sólo fue posible gracias a los cambios sociales del primer tercio del siglo $\mathrm{XX}^{34}$.

Rastrear los ejemplos de estas otras representaciones más plurales, más libres, más auténticas si se quiere, continúa, empero, lastrado por ese olvido interesado del sexo femenino como actante artístico. Si las referencias a grandes artistas españolas del siglo XX como Maruja Mallo, la más moderna de todas en su vida y la más vanguardista en su obra ${ }^{35}$, se hallan en un número sorprendentemente reducido de investigaciones, no resulta extraño encontrar meras insinuaciones a la obra del resto de mujeres de la misma órbita con no menos excepcional producción. Con demasiada frecuencia se asume el movimiento de vanguardia español como conquista masculina, espoleada por las entrañas de la Residencia de Estudiantes con su inestimable triada Lorca-Buñuel-Dalí - polígono del que, por cierto, deliberadamente se ocultó la impronta de Mallo-. Existieron, en cambio, un número considerable de mujeres -asumiendo que, con toda probabilidad, hubo muchísimas más voces acalladas de las que aún no tenemos constancia; o de las que nos ha llegado tan sólo un susurro, como en el caso de Ángeles Santos- que se negaron a continuar aquellas recomendaciones sugeridas por Joaquín de Mora como más propias para las habilidades prácticas del bello sexo.

Hubo mujeres que desafiaron su papel de complemento circunstancial para tipificar, tanto en su obra como en su proyección física, el nuevo ideal de feminidad que había germinado en la inmediata posguerra alentado desde el feminismo y la reciente dinámica industrial.

Dice Shirley Mangini que la denominada «mujer nueva» o «mujer moderna», emerge a principios del siglo XX como adalid de la modernidad, reflejando en su atavío los avances tecnológicos y sociales que el cambio de siglo trajo consigo ${ }^{36}$. Más aún, la estética singular de lo que vendría a denominarse en Francia como garçonne se desarrollaría en toda Europa y Estados Unidos como emblema de la mujer emancipada, que había superado el umbral privado reemplazando a la mano de obra masculina reclutada en el frente bélico, probando con ello una valía física e intelectual que los científicos tanto se habían afanado en probar imposible. Parece lógico que el devenir estético de una nueva figura, moldeada ya por manos femeninas, concluyese precisamente en un proceso de desfeminización para nada superficial, que alteraba la simbología telúrica de la cabellera, las formas voluptuosas que imponía el férreo corsé y todas aquellas prácticas sociales urdidas por la mente masculina, que habían desembocado en una hermética mística de la feminidad exquisita artificiosa y falaz ${ }^{37}$.

33 Plaza Aguado, I. (2014). Imágenes femeninas en la poesía española de preguerra (1900-1936) (Tesis doctoral). Universidad de Salamanca, Salamanca.

34 Ibíd., 47

35 Kirkpatrick, S. (2003). Mujer, modernismo y vanguardia en España (1898-1931). Madrid: Cátedra, 223.

36 Mangini González, S. (2001). Las modernas de Madrid: las grandes intelectuales españolas de la vanguardia. Barcelona: Luis Tasso, 74-75.

37 «Que a comienzos del XX y a nivel internacional occidental aparezcan y se consoliden de modo aproximadamente simultáneo el término "feminismo" y las imágenes de la garçonne y la flapper es un claro síntoma de que hubo un periodo histórico en el que las mujeres como colectivo invirtieron una gran energía en cuestionar, a la par que el orden establecido, las generales prerrogativas del sexo masculino y las imágenes de la feminidad que 
Contraria a ese caduco ideal de feminidad, la Mujer Moderna no es un garçon, sino, y claramente, una garçonne ${ }^{38}$; realmente podía ser cualquier cosa ${ }^{39}$.

Una mujer que adquiere hábitos y prácticas otrora vetados o acaso no contemplados en los márgenes de la feminidad decimonónica, y que los incorpora dentro de un imaginario novedoso. En el caso del tabaco, Jordi Luengo ${ }^{40}$ constata la transición desde lo indecoroso de su consumo por parte de las señoritas, hacia la tolerancia y posterior encumbramiento de una práctica antes masculina en aras de una imagen sensual que resalta ciertos encantos femeninos.

De cualquier modo, la conquista del tabaco por parte de las mujeres debe enmarcarse dentro de las transformaciones del ocio y las relaciones sociales que florecían ahora, en la ciudad industrial, con un vértigo inusitado. En cierto sentido, los $p a-$ raísos artificiales estimulados por el consumo de todo tipo de estupefacientes, se democratizaron con la llegada de los nuevos escenarios de ocio nocturno (cabarets, music-halls...), que propiciaron el acceso a la mujer al terreno de la bohemia más decadentista, anteriormente reservada al varón romántico maldito y marginado. El consumo de cocaína, morfina u opio era visto como sinécdoque de modernidad y sofisticación, pero actuaba al mismo tiempo para las señoritas de buena familia como acto subversivo que daba al traste con la indolencia decimonónica al consumirse en contextos abiertamente públicos; la necesidad de evasión e introspección resultaba mucho más comprensible en el caso del colectivo femenino, limitado históricamente al espacio doméstico, y la predisposición a esta clase de vicio idéntica en ambos sexos. De tal suerte, la Mujer Moderna termina resignificando prácticas masculinas, afianzando una bohemia femenina al probarse capaz de alcanzar idéntica corrupción física y moral $^{41}$.

\subsection{Delhy Tejero: la bruja moderna}

En este contexto la figura de Delhy Tejero sorprende por su anticipación tanto o más que por el desconocimiento general acerca de una artista de profesión, epítome perfecto de la Moderna como mujer que había normalizado la autonomía económica y. social; la mejor representación de ese nueva iconicidad femenina que paulatinamente habría penetrado en la realidad más popular a través especialmente de los semanarios ilustrados, acercando en la medida de lo posible a las muchachas de pueblo la posibilidad de emular la estética del cosmopolitismo de las altas esferas ${ }^{42}$.

les prefabricaba la sociedad». Expósito García, M. (2016). De la garçonne a la pin up. Mujeres y hombres en el siglo XX. Madrid: Cátedra, 167-68.

38 «El término garçonne no supone una simple feminización de un término masculino como garçon. Cercana al "sexo humano" o al neutro "ello", abre nuevos espacios simbólicos. "Soy garçonne" libera un nuevo sentido de la palabra masculina garçon y así da al traste con una convención que la fija en un referente masculino. ¿Qué significa feminizar una palabra que sólo se dice en masculino? ¿Qué, si además se trata de una que sirve para establecer la masculinidad en el tramo de vida que corresponde a la juventud, ese momento crucial en el que se está definiendo la identidad de género?». Ibíd., 172.

39 Lily Litvak observa que «la figura de la joven moderna era plurivalente, y tan elástica que cubría una multiplicidad de imágenes diversas: asexualidad e hipersensibilidad, independencia femenina y superficialidad, orden social y subversión». Kirkpatrick, S. (2003). Op. cit., 223.

40 Luengo López, J. (2008). Gozos y ocios de la mujer moderna: transgresiones estéticas en la vida urbana del primer tercio del siglo XX. Málaga: Servicio de publicaciones de la Universidad de Málaga.

41 Ibíd., 197.

42 Pérez Rojas, F. J. (2001). Modernas y cosmopolitas: La Eva art decó en la revista Blanco y Negro. En Camacho Martínez, R. y Miró Domínguez, A. (Eds.). Iconografía y creación artística: estudios sobre la identidad feme- 
Nacida Adela Tejero Bedate en Toro (Zamora) en un año, 1904, que nunca quiso afirmar, comienza a firmar en 1929 como Delhy, apócope inspirado por la capital de la India que enlaza a la perfección con ese anagrama con que se explotó el exotismo de Theda Bara (arab death). Delhy era, ante todo, una mujer extravagante y misteriosa; confeccionaba su propia ropa, se pintaba las uñas de negro y fumaba en boquilla. Formada en la Escuela de Bellas Artes de San Fernando, en contra de los deseos paternos, Delhy no se integró en ninguna corriente artística de manera concreta. Más bien transitó por todo aquello que le interesaba y con lo que podía vehicular más adecuadamente los sentimientos e ideas que tan efusivamente vertió en sus Cuadernines, pequeños diarios en los que volcaría su particular modo de entender el arte y la vida.

Desde un regionalismo inicial, muy influenciado por la obra de Romero de Torres, se deja sentir en la obra de Delhy un sabor decó que evoluciona hasta la abstracción, pasando por el tardocubismo y el postsurrealismo. Destaca, en su etapa final (años 50) un estilo que ella misma denominó Perlismo, un cierto informalismo tremendamente matérico, de formas inorgánicas, minerales, que proyectan una belleza cromática única. No es posible hablar en la obra de Delhy de parcelas estilísticas aisladas y concretadas en determinados periodos, se trata más bien de preferencias, como ella misma expresa:

Me parece sinceramente que la gran libertad de un artista está en hacer en cada momento lo que siente y lo que quiera. Y no vale la pena hacer el esfuerzo de recordar dónde se llega, para no moverse del sitio donde se está, cuando uno está convencido de que se estuvo muchas veces en sitios que se dejaron. ${ }^{43}$

Desde la figuración a la abstracción, Delhy pintó paisajes con un anhelo muy propio de los impresionistas a los que admiraba, pero son sin duda sus personajes, llenos de matices y destellos de su personalidad, los que alcanzan una magia inusual. En este sentido, resulta complicado describir la producción de Delhy Tejero conforme a tendencias artísticas o rasgos estilísticos concretos. En su trayectoria es posible distinguir diversas etapas que emanan de los muy diferentes influjos que recibió en sus viajes y experiencias en la convulsa España de entreguerras. Su personalidad, compleja y llena de matices, da como fruto una riquísima obra artística que se complementa con su faceta literaria de pequeños cuentos que también ilustraba.

No es momento de detenerse en sus avatares biográficos, ya ampliamente abordados en diversas publicaciones, pero merece la pena recordar algunos hitos de su carrera que permiten comprender su trascendencia artística:

En 1932 obtiene la medalla a las artes decorativas en la Exposición Nacional de Bellas Artes. Tan sólo un año antes, en 1931, es nombrada profesora especial interna de pintura mural en la Escuela de Artes y Oficios de Madrid, cuyo ambiente viciado refleja con resignación:

nina desde las relaciones de poder (pp. 235-288). Málaga: Centro de Ediciones de la Diputación de Málaga (CEDMA), 239.

43 Navarro Talegón, J. (1980). Delhy Tejero: notas para una biografía. En Catálogo de la exposición realizada por la Caja de Ahorros Provincial de Zamora (noviembre-diciembre), Zamora, 6. 
Salir de la Escuela [de San Fernando] como se sale y darme una cátedra tan difícil, sin precedentes, que tuve que confeccionar el programa... La lucha en la Escuela de Artes y Oficios con todos aquellos señores viejos, que, por ser ellos tanto y yo tan joven, me miraban con precaución y dureza, fingiendo indiferencia... No sé cómo definirlo... pero sola, yo sola siempre. ${ }^{44}$

La soledad es realmente un rasgo decisivo en la trayectoria de la artista junto con su pasión viajera. Como el resto de las modernas españolas, viaja muy pronto a Bruselas, Tánger y Fez, donde reside desde 1936 a 1937 sorprendida por la Guerra Civil. Y lo hace sola, con las dificultades esperadas por su condición de mujer y una independencia posibilitada por sus ingresos. Reside también en las ciudades italianas de Turín, Verona, Venecia, Roma, Nápoles, Pompeya y Florencia, donde estudia en la Escuela de Pintura Mural de San Marcos. En 1938 se traslada a París entrando en contacto con el surrealismo, exponiendo de hecho en la muestra Le rêve dans l'art et la littérature, en la que participaron Miró, Óscar Domínguez, Man Ray, Chagall, Klee...

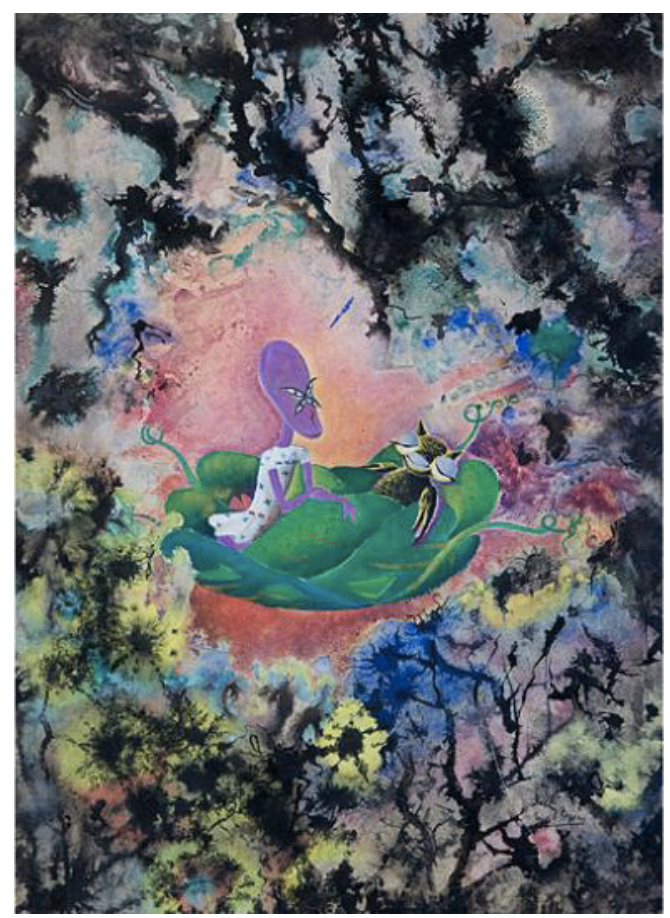

Figura 1. Kariko dormido. Serie Las Brujas (1930-36). Tintas y gouache sobre papel. Fuente: www.delhytejero.com

A su regreso a España expone en diversas exposiciones, siendo galardonada en numerosas ocasiones en las Exposiciones Nacionales. En 1953 su obra engrosa la primera exposición de arte abstracto; en 1954 expone en la Bienal de La Habana jun- 
to a figuras como Vázquez Díaz o Pablo Gargallo. Ya en los 60 su actividad se orienta de lleno en la pintura mural, con trabajos especialmente para iglesias de varios pueblos de la geografía española. En 1966 decide viajar por última vez a París para constatar la muerte definitiva del surrealismo, la única corriente artística que verdaderamente integró. Fallece en Madrid, un día gris del octubre de 1968, llena de arte.

Dos ejemplos de su variado y extenso repertorio artístico sirven para atisbar la modernidad que atesoraba la figura de Delhy. Dos ejemplos que ilustran la representación femenina confeccionada desde el conocimiento y la evidencia; a Castilla, tuétano y esencia, «la pintaría de un modo distinto. Sin forma determinada [...] Castilla es muy grande para reducirla a una casita y un árbol, a un rebaño o a una puesta de sol» $»^{45}$; a la mujer, condenada a un binarismo histórico, Delhy le ofreció un aliento diferente.

Huérfana de madre desde la infancia, Delhy desarrolló prontamente un sentido de la sororidad que, con la condescendencia habitual, se vinculó a las particularidades de su género. Kirta, Tarujita, Rabina o Kulinda, son pequeñas brujas que destierran la noción maligna y misógina de las mujeres sabias (y viejas), para ayudar e inspirar a la artista en su taller. Traviesas, diminutas, autónomas y trabajadoras, son capaces de dominar la tierra, el agua, los seres vivos y el cielo ${ }^{46}$ gravitando en fondos de abstracción colorista [Fig.1] para volver al estudio a afilar los lápices que una vez las alumbraron [Fig. 2].

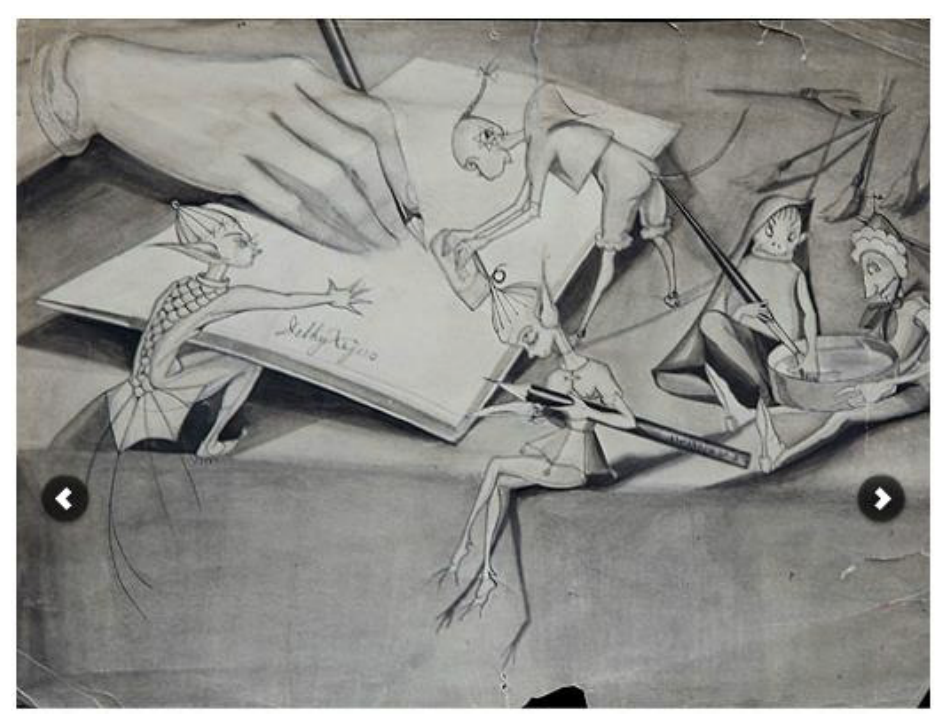

Figura 2. Serie Las Brujas (1930). Lápiz y tinta sobre papel.

Fuente: www.delhytejero.com

No sorprende que el desparpajo, tamaño y vitalidad de estos pequeños seres de sentido apotropaico fuera adecuado al discurso masculino con una maniobra practi-

\footnotetext{
45 Fuentes González, I. (1998). Delhy Tejero. Entre la tradición y la modernidad, 1904-1936. Zamora: Diputación de Zamora, 80.

46 Alario Trigueros, T. (2009). Op. cit.
} 
cada por los grandes pensadores del momento para con las artistas. Su genio (el de ellas) habría de venir canalizado por una fuerza telúrica universal e históricamente asociada a su sexo. «Se es una pintora como se es santa o se es adivina» ${ }^{47}$. Es decir, por gracia externa, divina, esotérica.

Ahora bien, cuando este misticismo es aplaudido y potenciado por la propia creadora, tan sólo cabe ridiculizar su valor simbólico (sororidad, pensamiento, trabajo, actividad) en el infantilismo de lo tierno, de la fantasía crédula e inocua, de ese preciosismo tan femenino. Las brujas de la aviación, de la astronomía y de la literatura, pasan a ser «las brujillas de la gracia, de la coquetería, de la presunción, del ornato, del mimo, del ensueño, de la venustidad, del mohín, de la sonrisa» ${ }^{48}$.

Rescatar el significado de las brujas de Delhy supone no sólo la asimilación de un nuevo emblema de la brujería femenina alejado del imaginario infantil (y colectivo) de maldad inherente a ciertas mujeres (ancianas, vanidosas, autónomas). Sino reconocer una nueva óptica de la mujer como sujeto artístico, que enfatiza en las redes de apoyo mutuo experimentadas por Delhy en su estancia en la Residencia de Señoritas y la Escuela de Bellas Artes y, por extensión, en los atributos de ese nuevo tipo de feminidad.

La artista ofreció, también y sin embargo, otra opción alternativa como paradigma de la Nueva Mujer, más cercana al reflejo estético que ella misma proyectaba, y que puede vincularse fácilmente con artistas coetáneas como Tamara de Lempicka y su tipificación canónica de la feminidad más letal.

Cuando en el año 1925 Delhy abandona su Toro natal para iniciar su formación artística, primero en la Escuela de Artes y Oficios entre los años 1925 y 1926 y, a partir de éste último, en la Escuela de Bellas Artes de San Fernando hasta 1929, la independencia económica era un asunto vital para la subsistencia en la capital madrileña. En los primeros años la artista disfrutó de una beca de estudios concedida en el marco de la Dictadura de Primo de Rivera, pero tras el cambio de gobierno de 1930 su fuente de ingresos se retiró y Delhy acudió a la ilustración como solución económica. Instalada en la Residencia de Señoritas, establecimiento creado por María de Maeztu como reflejo de la Residencia de Estudiantes masculina para ofrecer a las jóvenes no sólo una intensa formación intelectual profesionalizante sino, y lo que es más importante, un ambiente corporativo fructífero, la artista se dedicó a vender dibujos de trajes regionales a sus compañeras $^{49}$.

Precisamente ilustraciones de mujeres regionales fueron inaugurales en su fértil colaboración en la Prensa Gráfica. A partir de 1930 revistas como Crónica, $A B C$ o Estampa comenzaron a incluir semanalmente ilustraciones de la zamorana, como también lo hacían con los trabajos de temática infantil de Francis Bartolozzi, compañera y amiga de Delhy en la «Resi» y una nueva prueba de que la autonomía económica de las artistas solía entrecruzarse necesariamente con la ilustración gráfica. Serán estos trabajos simultaneados con los estudios artísticos

47 Molins, P. (2012). La heterogeneidad como estrategia de afirmación. La construcción de una mirada femenina antes y después de la Guerra Civil. Desacuerdos, (7), 73-74. Obtenido de: http://macba.es/uploads/publicacions/ desacuerdos/textos/desacuerdos_7/Patricia_Molins-pdf [Consulta: 6 de octubre de 2017]

48 Manuel Abril, "Delhy Tejero y sus brujas", Blanco y negro, 14 de enero 1934, citado en Fuentes González, I. (1998). Op. cit., 84

49 Ibíd., 43. 
los que permitan a mujeres como Delhy, Francis Bartolozzi o Remedios Varo ${ }^{50}$, traspasar la cerca del diletantismo decimonónico para explorar el terreno inédito de la autonomía artística (y financiera).

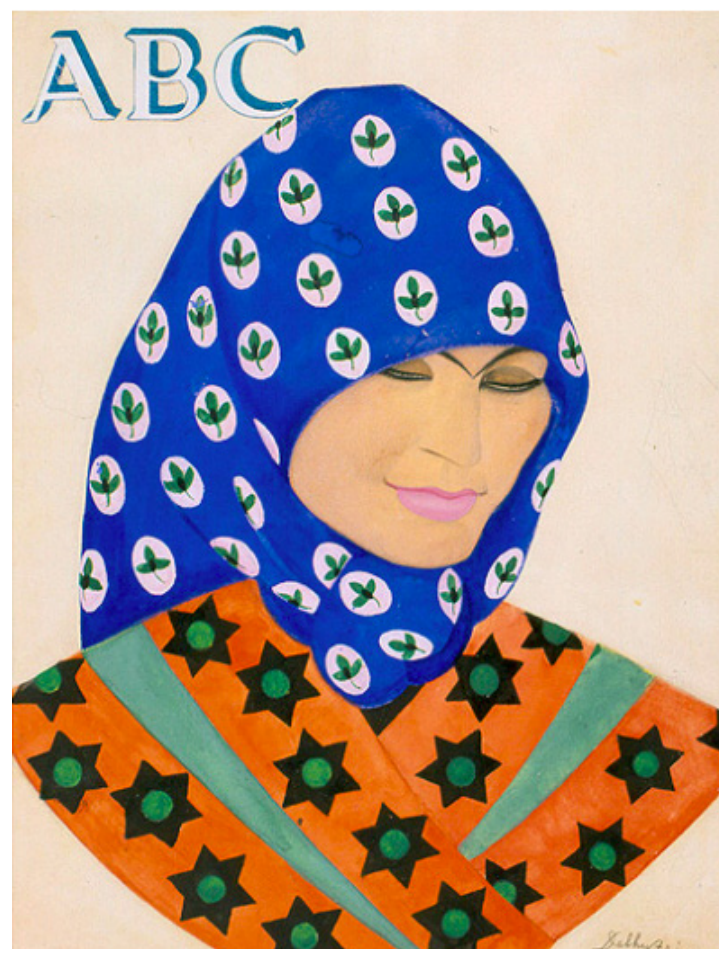

Figura 3. Zamorana (03/06/1934). Técnica mixta sobre papel. Fuente: www.delhytejero.com

Más allá de las ilustraciones femeninas de la geografía española incluidas en el semanario $A B C$ [Fig. 3] o en las Estampas españolas de La Esfera, la estética Decó estilizada y atractiva supera los tipos populares y encuentra su caudal iconográfico en la Mujer Moderna.

A la sección femenina habitual, se sumó la aparición en numerosas páginas de estas revistas de actrices, bailarinas, cantantes, profesionales nuevas como escritoras, pintoras o políticas, y especialmente, mujeres anónimas que cristalizaban poco a poco la estética y actitudes modernas ${ }^{51}$.

50 Ver Lozano Bartolozzi, M M. (2001). Artistas plásticas españolas entre dos guerras europeas: Pitti (Frances) Bartolozzi, Delhy Tejero, Remedios Varo. En Camacho Martínez, R. y Miró Domínguez, A. (Eds.), Iconografía y creación artística..., 289-328.

51 Patricia Molins advierte certera la importancia de las periodistas, como Josefina Carabias, que engrosaban las secciones dedicadas a las lectoras, en la visibilización de cuestiones inéditas como el trabajo femenino o la reciente controversia en torno al voto: «En el reportaje que hizo sobre este asunto en el norte de España tuvo buen cuidado en seleccionar mujeres de procedencia muy diversa, para mostrar el alto grado de politización de las mujeres y su interés por los mítines, entrevistando a oradoras de diferentes partidos». Molins, P. (2012). Op. cit., 69. 


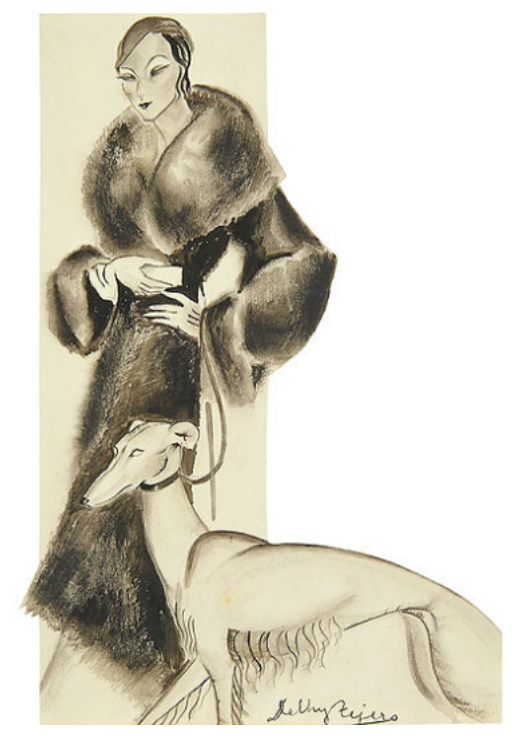

Figura 4. La Venus Bolchevique (1932). Tinta sobre papel recortado.

Fuente: www.delhytejero.com

En este contexto se enmarcan las ilustraciones realizadas por Delhy Tejero para el folletín La Venus Bolchevique de Francisco Carretero en la revista Crónica. La protagonista, auténtica femme fatal por definición, aglutinaba todos los presupuestos estéticos y consuetudinarios del cosmopolitismo de los años 20 que se había afianzado tras la primera contienda bélica. Espía, ejecutiva, misteriosa y atractiva, Olga Kuprin suplantaba el canon griego para definir una nueva deidad elegante, urbana y profesional [Fig. 4], «que puede tomar decisiones, pilotar aviones o conducir coches» ${ }^{52}$. Una particular Venus de líneas curvas y estilizadas ataviada con las mejores pieles y la arrogancia que Tamara de Lempicka había logrado tipificar en retratos como el de la $\mathrm{Du}$ quesa de La Salle (1925) o su propia proyección a bordo de un Bugatti verde en 1929.

La feminidad casi fatal de Delhy se resuelve, de hecho, perfectamente corpórea como identidad femenina moderna dentro de estas ilustraciones, del mismo modo que la personalidad hedonista y superflua con la que es referida Tamara de Lempicka encuentra en sus obras un perfecto reflejo.

Se trata precisamente de eso.

La representación de este nuevo prototipo de feminidad a manos de una mujer incide de nuevo en el camino de la autorrepresentación y la re-construcción del sexo femenino. Hacerlo supuso rebasar la frontera de las construcciones ad hoc de las mujeres lánguidas y de belleza medusea para la delectación del espectador masculino, abrazando una estética de liberación corporal y sexual que aprovechaba ciertas ventajas:

Quedará siempre en manos de la mujer el más legítimo de sus resortes de dominación, el encanto sexual, con el que no se gobierna el mundo, pero sí a los hombres que lo dirigen. ${ }^{53}$

Alario Trigueros, T. (2009). Op. cit., 6.

53 Gregorio Marañón citado en Mangini, S. (2001), Op. cit., 105. 
La diferencia estriba, de nuevo, en las manos que moldean esta nueva efigie. Brujas jóvenes y bondadosas o enigmáticas espías que dirigen un banco en secreto suponen varios senderos abiertos por la generación de mujeres artistas e intelectuales más relevante de la historia de España. Artistas que miran en derredor para retratar a las Madres de la guerra (1937) [Fig. 5] envueltas en la vorágine de la Guerra Civil. Esfumado el sabor del cosmopolitismo de los años veinte y las conquistas republicanas, las madres plañideras por los desastres de la guerra a las que se les arrebata el fruto de su vientre, se alejan de las ciudadanas viajeras, libres y profesionales.

Mujeres negras, de la más negra España. Mujeres, al fin y al cabo.

Mujeres que retratan mujeres. De eso se trata.

Mujeres en un camino hacia la descodificación de las apariencias impostadas desde el ojo masculino. De rebeldía, improvisación y experimentación. De autonomía y libertad.

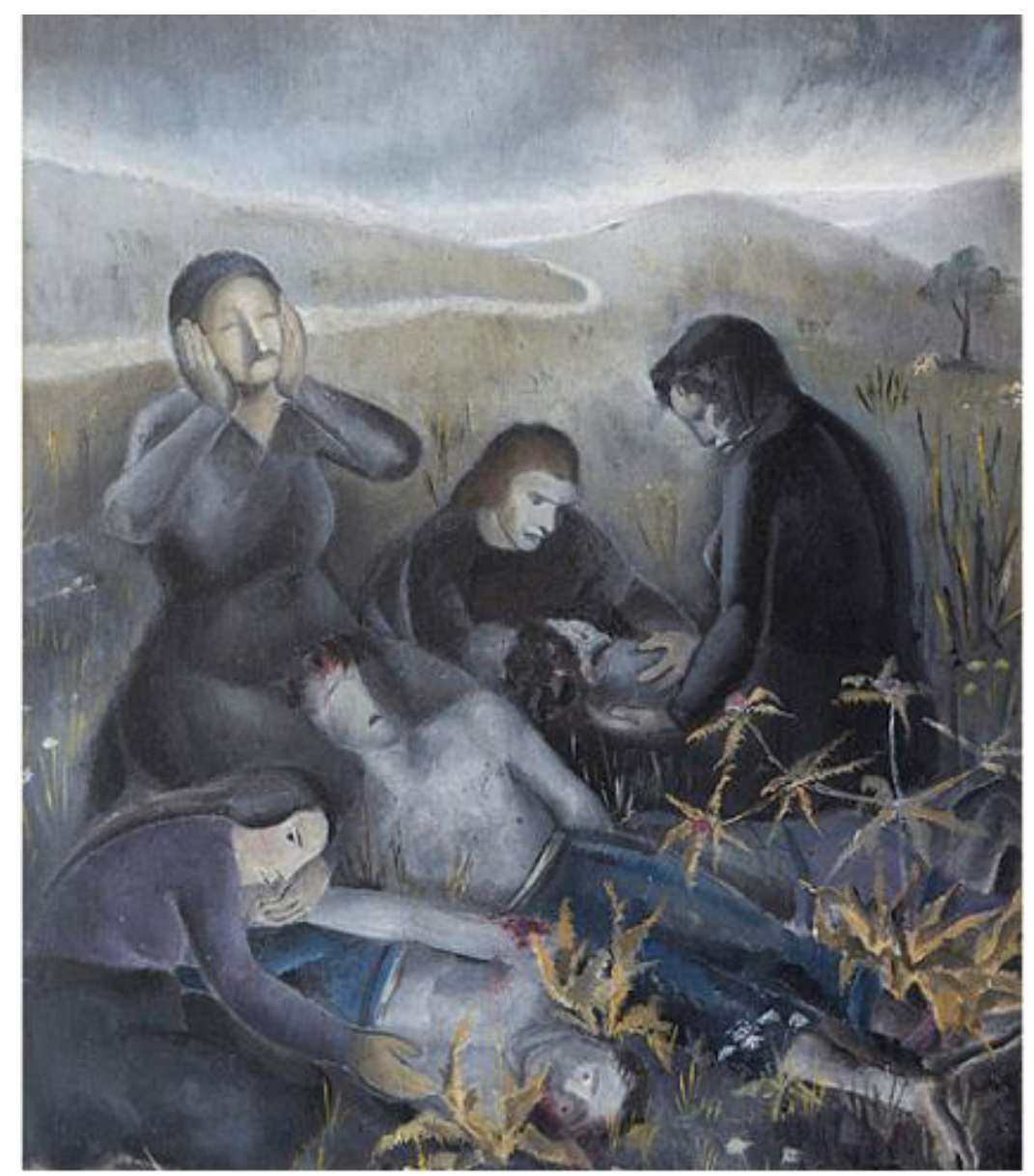

Figura 5. Madres de la guerra (1937). Óleo sobre lienzo. Fuente: www.delhytejero.com 